\section{Outbreak of nosocomial bacteremias, caused by Enterobacter gergoviae and Enterobacter aerogenes, in the neonatal intensive care unit, case - control study}

\author{
NATAŠA BOBAN • ANA JERONČIĆ • VOLGA PUNDA-POLIĆ
}

NATAŠA BOBAN $(\square)$

Department of Clinical Epidemiology University Hospital Split and University of Split School of Medicine Spinčićeva 1, 21000 Split, Croatia Phone: +38521556535 Fax: + 38521556169

E-mail: natasa.boban@st.htnet.hr

VOLGA PUNDA-POLIĆ Department of Clinical Microbiology University Hospital Split and University of Split School of Medicine Spinciceva 1, 21000 Split, Croatia

ANA JERONČIĆ Department for Research in Biomedicine and Health University of Split School of Medicine Soltanska 2, 21000 Split, Croatia

\begin{abstract}
In this case-control study we describe epidemiological characteristics and evaluate risk factors for bacteremias caused by a rare human pathogen Enterobacter gergoviae, and Enterobacter aerogenes, among neonates in the intensive care unit, under conditions of nosocomial outbreak.

Crude rate of bacteremias was 16 per 1000 admissions. Bacteremias most commonly occurred between 7 th to 30 th day of hospitalization and were 1.9 times more frequent in males than females. The following risk factors were significantly associated with the development of bacteremias: a) colonization or infection of neonates prior to the onset of bacteremia with Enterobacter spp. $(\mathrm{OR}=3.4,95 \% \mathrm{Cl}=1.2-9.9)$ or non-Enterobacter spp. $(\mathrm{OR}=7.9,95 \% \mathrm{Cl}=1,2-52.5)$; b) use of antimicrobial drugs most notably ceftazidime ( $O R=7.8,95 \% \mathrm{Cl}=1.6 .-38.6)$, or amikacin ( $O R=7.5,95 \% \mathrm{Cl}=2.8$-19.9); and c) invasive interventions: mechanical ventilation $(O R=4.7,95 \% \mathrm{Cl}=1.6-13.5)$, umbilical catheterization $(O R=3.1,95 \% \mathrm{Cl}=1.1$ 13.3), or nasogastric tube insertion ( $O R=3.8,95 \% \mathrm{Cl}=1.8-8)$. These results show that some previously described risk factors for developing Enterobacter bacteremia were equally applicable in the case of Enterobacter gergoviae infections. In addition, the report represents an important contribution to establishing E. gergoviae as a relevant human pathogen with epidemiological potential, as it is the first case-control report in the region and one of a few in the world, analyzing outbreaks of bacteremias in the neonatal intensice care unit (ICU) caused by E. gergoviae.
\end{abstract}

Key words: neonatal intensive care unit, bacteremia, Enterobacter gergoviae, Enterobacter aerogenes, risk factors

\section{Introduction}

Enterobacter spp. was not considered a cause of nosocomial infections until 1970. $(1,2)$ In the last decades, however, hospital-acquired Enterobac- ter bacteremias have been increasingly reported, especially in intensive care units (ICUs). (3-8) In addition to that, species of the genus Enterobacter show increasing resistance to antimicrobial drugs. (1-3,5,9-11)

Enterobacter bacteremia rates are around 1 per 1000 admissions for university hospitals and tertiary health care institutions. Rates are usually two to three times higher in specialized units, such as oncology departments. $(1,4)$ In contrast to general hospitals, studies of Enterobacter bacteremias occurring in pediatric hospitals, (12-14) and in neonatal ICUs $(6,15,16)$ are rather scarce. Bacteremias caused by species of the genus Enterobacter are 1.3 to 2.5 times more common in males, neonates and the elderly $(1,12)$ and mortality asso- 
ciated with Enterobacter bacteremias ranges between $20 \%-35 \%$ in all age groups. (12)

Risk factors for Enterobacter bacteremia are different in adults and children, especially neonates. For neonates, immunosuppression of any cause, early gestational age, low birth weight, as well as usage of invasive devices (central venous catheters, endotracheal tubes, urinary catheters) and antimicrobial drugs, were connected with a greater risk of Enterobacter bacteremias.

$(1,4,6,14,17,18)$ Antimicrobial resistance, especially towards beta-lactam antibiotics, (19) in addition to other risk factors, was associated with several outbreaks caused by species of the genus Enterobacter in neonatal ICUs. $(6,16,20,21)$

In this case- control study we evaluated the risk factors for bacteremias caused by a rare human pathogen Enterobacter gergoviae, and Enterobacter aerogenes among neonates in the intensive care unit under conditions of nosocomial outbreak.

\section{Materials and Methods}

The investigation was conducted from January $1^{\text {st }}, 1995$ until December 31st, 1996 at the Neonatology Unit of the Department of Obstetrics and Gynecology University Hospital Split and was approved by the Ethics Committee of the University Hospital Split.

A matching case - control method was implemented. A case was every neonate admitted to the ICU, from whose blood culture Enterobacter spp. was isolated and who had clinical signs of illness. The control group represented neonates admitted to the Unit at the same time, with sterile hemocultures and no clinical signs of blood infection. Controls were matched according to gestational age, birth weight and time of hospitalization (only case-control pairs that were hospitalized at the same time). Cases were compared with respective controls in relation to their exposure to potential risk factors for enterobacter bacteremia.

The following potential risk factors for developing Enterobacter bacteremias were analyzed: a) duration and characteristics of delivery (vaginal or cesarean section; umbilical cord damage; prolapse or wrapping of the cord around the neonates neck; meconial, milky or bloody amniotic fluid; Apgar score), b) characteristics of the neonate in terms of gestational age and birth weight (premature or full term delivery; first or second twin; birth weight; mode of hospitalization - incubator, baby-term, or standard bed), c) implementation of invasive procedures (mechanical ventilation; umbilical catheterization; nasogastric tube insertion), d) drugs used, e) blood derivatives received (concentrated erythrocytes; exsanguino-transfusion; thrombocytes; immuno-globulins; plasma; human albumins), f) way of feeding (breast, bottle, parenteral), g) microbial flora isolated from ear, nose, throat, rectum swabs and hemocultures on admission and during hospitalization, and h) maternal characteristics. Maternal characteristics evaluated as risk factors included: mother's age, education, place of residence, number of gestations, abortions, deliveries and complications during pregnancy. A detailed questionnaire with specified epidemiological data was developed and completed for every case and control.

Bacteremia was defined as a laboratory confirmed bloodstream infection. All neonatal infections, with the exception of proven transplancental infections, were considered nosocomial. (22) Bacteremias in neonates were classified as: very early (infections diagnosed within the first 48 hours from admission, usually acquired from the mother during passage through the birth canal), early (bacteremias developed after delivery, between 2 to 7 days of hospitalization), late (between 8 to 30 days of hospitalization) and very late (after more than 30 days of hospitalization). (22)

The rate of bacteremias was expressed as a proportion of patients with bacteremia relative to the number of admissions to the department.

Blood for hemocultures was placed on a liquid media for aerobic and anaero- bic bacteria, and incubated in an automatized machine for hemoculture Vital (bio Merieux, Marcy d'Etoile, France). Identification of Enterobacter species was based on biochemical characteristics using standard microbiological methods, and confirmed with API 20E (bio Merieux). Susceptibility to antimicrobial drugs was determined using the disk diffusion method.

Pearson's chi-square and contingency tables were used for the analysis of qualitative variables. Differences in frequencies of the events between the groups were evaluated at the significance level of alpha $=0.05$.

For evaluating the strength of the relationship between risk factors and illness, odds ratio was used. 95\% confidence interval, $(95 \% \mathrm{Cl})$, was used to indicate the reliability of an odds-ratio estimate.

\section{Results}

During the observed period of two years, a total of 64 (42 male and 22 female) cases were included, with an average body mass of $2795 \mathrm{~g}$ (ranging from 1050 to $4750 \mathrm{~g}$ ) (table 1). Average length of stay in the ICU was 33.5 days (from 9 to 91 days). The control group consisted of 64 (42 male and 22 female) neonates, with an average mass of $2863 \mathrm{~g}$ (ranging from 1250 to $4200 \mathrm{~g}$ ), and average length of stay in the ICU of 22 days (from 5 to 64 days).

In 1995, 21 bacteremias were diagnosed, and in 1996, 43 bacteremias. The rate of bacteremias per 1000 admissions was 10 in 1995 and 22 in 1996, with an average rate of 16 per 1000 admissions. Bacteremias were more common in male neonates with an average ratio of 1.9 relative to female neonates.

From a total of 64 neonates with bacteremia, 6 (9.4\%) died, with bacteremia caused by $E$. gergoviae, so mortality connected with that bacteria was $13.9 \%$ (table 1). In the control group, no neonates died.

The distribution of incidence of bacteremias by the time of bacteremia onset and by the causal Enterobacter species is shown in table 2. Bacteremias most commonly occurred between $7^{\text {th }}$ to $30^{\text {th }}$ day of hospitalization (56.3\%). 
Table 1. Neonatal Enterobacter bacteremias observed at the Department of Neonatology intensive care unit, University Hospital Split, during 1995 and 1996.

\begin{tabular}{|c|c|c|c|c|c|c|c|}
\hline Year & Bacteremias (n) & $\begin{array}{c}\text { Bacteremias } \\
\text { (rate } / 1000 \text { admi- } \\
\text { ssions) }\end{array}$ & $\begin{array}{c}\text { Gender } \\
(\mathrm{M}: \mathrm{F})\end{array}$ & \multicolumn{2}{|c|}{$\begin{array}{c}\text { Hemoculture } \\
\text { isolates } \\
\text { E. aerogenes E. gergoviae }\end{array}$} & \multicolumn{2}{|c|}{ Mortality } \\
\hline 1995. & 21 & 10 & $4: 1$ & 12 & 9 & 0 & 0 \\
\hline 1996. & 43 & 22 & $1.4: 1$ & 0 & 43 & 6 & 13.9 \\
\hline $\begin{array}{c}\text { Total / } \\
\text { Average }\end{array}$ & 64 & 16 & $1.9: 1$ & 12 & 52 & 6 & 9.4 \\
\hline
\end{tabular}

Table 2. Distribution of bacteremias by the time of the onset and the causal Enterobacter species.

\begin{tabular}{|c|c|c|c|c|c|c|}
\hline \multirow{2}{*}{$\begin{array}{c}\text { Bacteremia } \\
\text { (time of onset) }\end{array}$} & \multicolumn{2}{|c|}{ E. aerogenes } & \multicolumn{2}{|c|}{ E. gergoviae } & \multicolumn{2}{|c|}{ Total } \\
\hline & (n) & $(\%)$ & (n) & $(\%)$ & (n) & (\%) \\
\hline Very early (within 48 h) & 0 & 0 & 3 & 5.8 & 3 & 4.7 \\
\hline Early $\quad$ (2 to 7 days) & 5 & 41.7 & 19 & 36.5 & 24 & 37.5 \\
\hline (8 to 30 days) & 7 & 58.3 & 29 & 55.8 & 36 & 56.2 \\
\hline Very late (after 30 days) & 0 & 0 & 1 & 1.9 & 1 & 1.6 \\
\hline Total & 12 & 100 & 52 & 100 & 64 & 100 \\
\hline
\end{tabular}

Table 3. Neonates that developed Enterobacter bacteremia according to maternal characteristics.

\begin{tabular}{lll}
\hline Characteristic of mothers & $\mathrm{n}$ & $\%$ \\
\hline Mothers age (years) & & \\
Less than 24 years & 21 & 32.8 \\
25-29 years & 11 & 17.2 \\
30-34 years & 18 & 28.1 \\
35 and more years & 12 & 18.8 \\
unknown & 2 & 3.1 \\
Mothers education & & \\
primary school or no education & 33 & 51.6 \\
secondary school & 25 & 39.1 \\
university & 6 & 9.3 \\
Mothers place of living & & \\
Split-urban area & 27 & 42.2 \\
Province hinterland & 37 & 57.8 \\
Gestation & & \\
first & 19 & 29.7 \\
second & 19 & 29.7 \\
third and more & 26 & 40.6 \\
Delivery & & 31.3 \\
first & & \\
second & & \\
third and more & 23 & \\
\hline
\end{tabular}

Very early and very late bacteremias were observed only in three and one case, respectively.

In table 3 the frequency distributions and percentages of newborns that developed nosocomial Enterobacter bacteremias are shown, in relation to the different characteristics of their mothers. Occurrence of bacteremias in the neonates was inversely proportional to the education of their mothers.

Regarding place of residence, neonates from mothers that lived in areas far from urban Split showed an increased tendency of developing bacteremia in comparison to neonates of mothers that lived in the city of Split, although this tendency did not reach statistical significance.

Colonization or infection of neonates prior to the onset of bacteremia was associated with a $3.4(95 \% \mathrm{Cl}=1.2-9.9)$ and $7.9(95 \% \mathrm{Cl}=1.2-52.5)$ times increased risk of developing bacteremia, due to Enterobacter and non-Enterobacter microbial agents, respectively (table 4).

The spectrum and incidence of use of different antimicrobial drugs was also 
Table 4. Microbial isolates from biological specimens of cases and controls before the onset of bacteremia.

\begin{tabular}{lllll}
\hline Microbial isolates & Cases & \multicolumn{3}{c}{ Controls } \\
\hline & $\mathrm{n}$ & $\%$ & $\mathrm{n}$ & $\%$ \\
Enterobacter $^{*}$ & 11 & 17.2 & 4 & 6.3 \\
non-Enterobacter $^{*}$ & 18 & 28.1 & 3 & 4.7 \\
no microbial isolates* $^{*}$ & 35 & 54.7 & 57 & 89.0 \\
\hline
\end{tabular}

* cases vs. controls, $p<0.05$

enterobacter $=$ species of genus Enterobacter $(\mathrm{OR}=3.4,95 \% \mathrm{Cl}=1.2-9.9)$

non-enterobacter $=$ species of genus Staphylococcus, Streptococcus, Escherichia, Acinetobacter, Proteus, Pseudomonas, Candida (OR=7.9, $95 \% \mathrm{Cl}=1,2-52 \cdot 5)$.

Table 5. Use of antimicrobial drugs in neonates before the onset of bacteremia.

\begin{tabular}{lllll}
\hline Antimicrobial drugs & Cases & \multicolumn{3}{c}{ Controls } \\
\hline & $\mathrm{n}$ & $\%$ & $\mathrm{n}$ & $\%$ \\
ampicillin & 62 & 96.9 & 54 & 84.4 \\
gentamicin & 19 & 29.7 & 19 & 29.7 \\
amikacin* & 44 & 68.8 & 6 & 9.4 \\
netilmycin & 37 & 57.8 & 32 & 50 \\
ceftazidime* & 33 & 51.6 & 6 & 9.4 \\
cefuroxime & 11 & 17.2 & 7 & 10.9 \\
\hline
\end{tabular}

${ }^{*}$ cases vs. controls, $p<0.05$

amikacin $(\mathrm{OR}=7.5,95 \% \mathrm{Cl}=2.8 .-19.9)$

ceftazidime $(\mathrm{OR}=7.8,95 \% \mathrm{Cl}=1.6-38.6)$

Table 6. Application of invasive interventions during hospitalization in cases and controls.

\begin{tabular}{lllll}
\hline Invasive interventions & \multicolumn{2}{c}{ Cases } & \multicolumn{2}{c}{ Controls } \\
\hline & $\mathrm{n}$ & $\%$ & $\mathrm{n}$ & $\%$ \\
no intervention & 42 & 65.6 & 55 & 85.9 \\
mechanical ventilation* $_{\text {nasogastric tube insertion* }}^{*}$ & 20 & 31.3 & 5 & 7.8 \\
umbilical catheterization* $^{*}$ & 37 & 57.8 & 17 & 26.6 \\
\hline
\end{tabular}

${ }^{*}$ cases vs. controls, $p<0,05$

mechanical ventilation $(\mathrm{OR}=4.7,95 \% \mathrm{Cl}=1.6-13.5)$

nasogastric tube insertion $(\mathrm{OR}=3.8,95 \% \mathrm{Cl}=1.8-8)$

umbilical catheterization $(\mathrm{OR}=3.1,95 \% \mathrm{Cl}=1.1-13.3)$

higher in the group of cases and was associated with an increased risk of developing bacteremia in the case of amikacin and ceftazidime (table 5).

Invasive interventions such as mechanical ventilation, nasogastric tube use and/or umbilical catheter insertion, were significantly more often applied in the group of cases and were associated with a higher chance of developing bacteremia (table 6).

Other potential risk factors for developing enterobacter bacteremias that were analyzed (duration and mode of delivery, umbilical cord related abnormalities, meconium stained, milky or bloody amniotic fluid, Apgar score, first or second twin, mode of hospitalization, administration of blood derivatives, type of feeding) showed no significant influence on the chances for developing bacteremias relative to the controls (data not shown).

\section{Discussion}

In this case-control study we describe epidemiological characteristics of Enterobacter bacteremia outbreaks in a neo- natal ICU and analyze major risk factors for development of bacteremias.

The nosocomial outbreak is indicated by the occurrence of 64 neonatal bacteremias during 2 years, with a crude rate of 16 per 1000 admissions. (22)

Enterobacter species isolated from the cases were E. aerogenes $(18,6 \%)$ and E. gergoviae (82\%), which is rather atypical, since the most frequently described Enterobacter isolates have been E. cloacae and E. aerogenes, and less frequently, E. agglomerans and $E$. sakazakii. $(1,2,5,21,22)$ 
Over the last decade, E. aerogenes has been identified more often as a cause of bacteremia outbreaks in hospitals $(3,7)$ as well as in ICUs $(16,23)$. Nosocomial outbreaks due to multiresistant $E$. aerogenes are an emerging concern in ICUs. Infections caused by this organism are often not detected at an early stage and are both difficult to control and to treat.

In contrast to these, E. gergoviae is a relatively rare human pathogen. $(4,24)$ It was only once described as a cause of bacteremias in a neonatal ICU in Asia. (25) E. gergoviae was first described in 1976 (26) and in 1980 was characterized in more detail as a new species of Enterobacteriaceae, found in clinical specimens and the environment. (27) Therefore, this report represents an important contribution in establishing $E$. gergoviae as a relevant human pathogen with epidemiological potential.

Our study also confirms the relevance of various established risk factors for developing Enterobacter bacteremias. $(15,17,18,20,21,28)$ Among these, we especially recognized the relevance of colonization or infecti- on of neonates prior to the onset of bacteremias, excessive use of certain antibiotics and application of invasive interventions. Our results also verify that length of stay in the neonatal ICU as a risk factor. The fact that the majority of bacteremias occurred after 7 days of hospitalization in the neonatal ICU indicate that the ICU served as a reservoir for colonization and infection of the neonates. (29) We also noticed that some maternal characteristics, such as education and place of living, might be associated with an increased tendency for neonates to develop bacteremias.

Although each of the mentioned risk factors can be independently justified, their separate analysis might not be appropriate because of the apparent interrelationship between them. For example, we believe that the initial risk might in part originate from the mother. Namely, a lower education and residence in remote areas of the province point to the poor socio-economic status of these mothers, which may pose a risk for the health of their babies. On the other hand, a tendency to and severity of illness in such babies is generally increased, which in turn is associated with more aggressive therapeutic and diagnostic procedures, thereby closing the chain of risk factors.

\section{Conclusion}

This is the first report in Croatia and the neighboring region, as well as one of a few in the world, describing an outbreak of bacteremias in a neonatal ICU caused by E. gergoviae.

We also showed that some previously described risk factors for developing Enterobacter bacteremia were equally applicable in the present case. Increasing survival of neonates with low birth weight and gestational age that require implementation of invasive methods and antimicrobial drugs, provide a favorable environment for the continuous presence of Enterobacter spp. as a cause of bacteremias in the neonatal ICU. Better understanding of epidemic characteristics and risk factors provide essential grounds for planning effective ways for infection prevention, the ever-increasing challenge.

\section{REFERENCES}

1. Sanders WE, Sanders CC. Enterobacter spp.: Pathogens poised to flourish at the turn of the century. Clin Microbiol Rev 1997;10:220-41.

2. Falkiner FR. Enterobacter in hospital. J Hosp Infect 1992;20:137-40.

3. Ronveaux O, de Gheldre I, Glupcynski Y, Struelens M, de Mol P. Emergence of Enterobacter aerogenes as a major antibiotic-resistant nosocomial pathogen in Belgian hospitals. Clin Microbiol Infect 1999;5:622-7.

4. Al Ansari, McNamara EB, Cunney RJ, Flynn MA, Smyth EG. Experience with Enterobacter bacteremia in a Dublin teaching hospital. J Hosp Infect 1994;27:69-72.

5. Acolet D, Ahmet Z, Houang E, Hurley R, Kaufmann ME. Enterobacter cloacae in a neonatal intensive care unit: account of an outbreak and its relationship to use of third generation cephalosporins. J Hosp Infect 1994;28:273-86.

6. Xu XF, Mia XL, Chen Z, Shi LP, Du LZ. Clinical characteristics of nosocomial infections in neonatal intensive care unit in eastern China. J Perinat Med 2010;38(4):431-7.

7. Chang EP, Chiang DH, Lin ML, Chen TL, Wang FD, Liu CY. Clinical characteristics and predictors of mortality in patients with Enterobacter aerogenes bacteremia. J Microbiol Immunol Infect 2009;42(4):329-35.

8. Gastmeir P, Andrea Loui A, Stamm-Balderjahn S, Hansen S, Zuchneid I, Sohr D, et al. Outbreaks in NICU-They are not like others. Am J Infect Control 2007;35(3):172-6.

9. Canton R, Oliver A, Coque TM, Varela MdC, Perez-Diaz JC, Baquero F. Epidemiology of extended-spectrum beta-lactamase-producing Enterobacter isolates in a spanish hospital during 12-year period. J Clin Microbiol 2002;40(4)1237-43.

10. Ho PL, Shek RH, Chow KH, Duan RS, Mak GC, Lai EL, et al. Detection and characterisation of extended-spectrum beta-lactamases among bloodstream isolates of Enterobacter spp. in Hong Kong, 2000-2002. J Antimicrob Chemoter 2005;55(3):326-32. 
11. Stock I, Wiedemann B. Natural antibiotic susceptibility of Enterobacter amnigenus, Enterobacter cancerogenus, Enterobacter gergoviae and Enterobacter sakazakii strains. Clin Microbiol infect 2002;8(9):564-78.

12. Pittet D. Nosocomial bloodstream infections. In: Wenzel RP, ed. Prevention and control of nosocomial infections. Baltimore: Williams\&Wilkins; 1995. pp. 711-70.

13. Gallagher PG. Enterobacter bacteremia in pediatric patients. Rev Infect Dis 1990;12:808-12.

14. Andresen J, Asmar BI, Dajani AS. Increasing Enterobacter bacteremia in pediatric patients. Pediatr Infect Dis J 1994;13:787-92.

15. Gaynes RP, Edwards JR, William R, Culver DH, Tolson JS, Martone WJ. Nosocomial infections among neonates in high-risk nurseries in the United States. Pediatrics 1996;98:357-61.

16. Liowal V, Kumar A, Gupta P, Gomber S, Ramachandran VG. Enterobacter aerogenes outbreak in a neonatal intensive care unit. Pediatr Int 1999;41:157-61.

17. Fok TF, Lee CH, Wong EM, Lyon DJ, Wong W, Ng PC, et al. Risk factors for Enterobacter septicemia in a neonatal unit: case-control study. Clin Infect Dis 1998;27(5):1204-9.

18. Drews MB, Ludwig AC, Leititis JU, Daschner FD. Low birth weight and nosocomial infection of neonates in a neonatal intensive care unit. J Hosp Infect 1995;30:65-72.

19. de Man P, Verhoeven BAN, Verbrugh HA, Vos MC, van der Anker JN. An antibiotic policy to prevent emergence to resistant bacili. Lancet 2000;355:973-8

20. Dalben M, Varkulja G, Basso M, Krebs VL, Gibelli MA, van der Heijden I, et al. Investigation of an outbreak of Enterobacter cloacae in a neonatal unit and review of the literature. J Hosp Inf 2008;70(1)7-14.

21. Yu WL, Cheng HS, Lin HC, Peng CT, Tsai CH. Outbreak investigation of nosocomial enterobacter cloacae bacteremia in neonatal intensive care unit. Scand J Infect Dis 2000;32(3):293-8.

22. Moore DL. Nosocomial infections in newborn nurseries and neonatal intensive care units. In: Mayhall CG, ed. Hospital epidemiology and infection control. Baltimore: Williams \& Wilkins; 1996. pp. 535-64.

23. Carlier E, Piagnerelli M, Lejeune P, de Gheldre Y, Struelens M, Glupczynski Y. Investigation of an outbreak of multiresistant Enterobacter aerogenes infection in an intensive care unit. Critical Care 1997;1(Suppl 1):P035

24. Chen KJ, Yang KJ, Sun CC, Yeung L. Traumatic endophtalmitis caused by Enterococcus raffinosus and Enterobacter gergoviae. J Med Microbiol 2009;58:526-8.

25. Ganeswire R, Thong KL, Puthucheary SD. Nosocomial outbreak of Enterobacter gergoviae bacteremia in a neonatal intensive care unit. J Hosp Inf 2003;53(4):292-6.

26. Richard C, Joly B, Sirot J, Stoleru GH, Popoff M. Etude de souches de Enterobacter apartenant a un groupe particulier proche de E. aerogenes. Ann Inst Pasteur 1976;127A:545-8.

27. Brenner DJ, Richard C, Steigerwalt AG, Asbury MA, Mandel M. Enterobacter gergoviae sp. nov.: a new species of Enterobacteriaceae found in clinical speciments and the enviroment. Int J Syst Bacteriol 1980;30:1-6.

28. Rojo D, Pinedo A, Clavijo E, Garcia-Rodrigez, Garcia V. Analysis of risk factors associated with nosocomial bacteremias. J Hosp Infect 1999;42:135-41.

29. Toltzis P, Hoyden C, Spinner-Block S, Salvatot AE, Rice LB. Factors that predict preexisting colonization with antibiotic resistant gramnegative bacilli in patients admitted to a pediatric intensive care unit. Pediatrics 1999;103:719-23.

\section{ACKNOWLEDGMENTS}

We express our gratitude and thanks to registered nurses Mrs Vesna Tomic and Mrs Anisija Velic, for their professional assistance in the management of outbreak and contribution in surveillance and data collection. 